\title{
Neuroendocrine neoplasm DFP report
}

Accepted: 18 November 2020

(c) Springer Science+Business Media, LLC, part of Springer Nature 2021

\section{Listing of Disease Focused Panel (DFP) members}

\section{DFP members}

Priya Bhosale, MD (Chair)

Ajaykumar C Morani, MD (Co-chair)

Motoyo Yano, MD (Chair of Pancreatic Neuroendocrine section)

Ajaykumar C Morani, MD (Chair of GI Neuroendocrine section)

Chandana Lall, MD (Co-chair of other AP Neuroendocrine Tumors section)

Sadhana Verma, MD (Co-chair of other AP Neuroendocrine Tumors section)

Malak Itani MD (Director of Protocol \& Template Management-anatomic imaging)

Dheeraj R Gopireddy, MD (Director of Education for Case of the Month)

Amir Iravani, MD (Director of Protocol \& Template Management—functional imaging \& theranostics)

Mohammed Saleh, MD

Isaac R Francis, MD

Kedar G Sharbidre, MD

Juan Ibbara Rovira, MD

Samuel Galgano, MD

Sanaz Javadi, MD

John Millet, MD, MHS

Manohar Roda, MD

Ajit Goenka, MD

Thomas Hope, MD

Silvana Faria, MD

Michael Blake, MD

Heather Jacene, MD

David D.B. Bates MD

Beth Chasen, MD

Hina Arif-Tiwari, MD

Smita Sharma, MD

\section{DFP consultants}

Daniel Halperin, MD (Chief consultant)

Mathew Katz, MD

\author{
Ching-Wei David Tzeng, MD \\ Emily Bergsland, MD \\ Palmela Kunz, MD \\ Manoop S. Bhutani, MD \\ Michael Frumovitz MD \\ Huamin Wang, MD \\ Koushik Das, MD \\ Deyali Chatterjee, MD \\ Nikolaos Trikalinos, MD \\ Hyun Kim, MD \\ Chet Hammill, MD \\ Jessica Maxwell, MD
}

\section{Look back}

Neuroendocrine neoplasms (NENs) are a diverse group of cancers that may involve multiple organ systems in the body. The annual incidence of NENs is gradually increasing due to improved detection by endoscopy and cross-sectional imaging. Despite the significant strides in the field of NENs over the past decade, there are still several opportunities for early and accurate diagnosis, improving prognostication, and maximizing quality of life for patients with NENs. Fortunately, the last decade has seen accelerating progress in our understanding and treatment of NENs. There have been several recent updates in the pathologic classification and nomenclature of NENs, with the updated WHO classification in 2019 , formally separating NENs into welldifferentiated neuroendocrine tumors (NETs) and poorly differentiated neuroendocrine carcinomas (NECs), which have distinctive genomics, epidemiology, and treatment paradigms. In addition, recent therapeutic advances include the regulatory approval of peptide receptor radionuclide therapy (PRRT) with ${ }^{177}$ Lu-DOTA-octreotate for patients with gastroenteropancreatic NETs in 2018. With this development, there is increasing focus on theranostics, which is critically dependent on diagnostic imaging. The latest regulatory approval of ${ }^{64} \mathrm{Cu}$-DOTA-octreotate, in September 
2020, adds another opportunity for PET imaging in NET, in addition to ${ }^{68} \mathrm{Ga}$-DOTA-octreotate.

In order to keep abreast with the advances in the field of NENs and to meet the needs for the care of NEN patients, the SAR neuroendocrine DFP was officially formed at the 2020 Annual meeting of the Society of Abdominal Radiology, to promote collaborative efforts among the diverse group of academic radiologists, oncologists, surgeons, pathologists, and radiation oncologists from different institutions in the United States. Its founding chairs are Drs. Priya Bhosale, Ajaykumar Morani, and Motoyo Yano. The lead oncology consultant is Dr. Daniel Halperin. Dr. Ajaykumar Morani is also chair of the GI neuroendocrine section, and Dr. Motoyo Yano is chair of the Pancreatic Neuroendocrine section. Drs. Chandana Lall and Sadhana Verma are the chairs of the other abdominopelvic neuroendocrine sections of the DFP. The mission of the DFP is to facilitate earlier diagnosis, better understanding of the pathophysiology, biological behavior, and natural history of NEN, and to stratify prognosis, improve assessment of treatment response, and impact the survival and morbidity of patients with abdominopelvic neuroendocrine tumors by augmenting the interdisciplinary collaboration, knowledge, and research within the radiology community by utilizing conventional and emerging imaging techniques.

In addition to creating a multidisciplinary diverse representative panel, the DFP's first effort was the successful establishment of a presence on the website of Society of Abdominal Radiology (link: https://www.abdominalradiol ogy.org/page/neuroendocrinedfp). The DFP also created a social media account on twitter (https://twitter.com/SARNE TDFP/status/1246984844879552512). Regular monthly meetings were held, and brainstorming on the knowledge gaps and opportunities in the field of abdominopelvic neuroendocrine tumors was started among the panelists. Experts in the field are invited every other month for educational web lectures at the DFP meetings. At the same time, the DFP also embarked on educational endeavors with the online publication of a monthly interesting neuroendocrine case by the members on the website of Society of Abdominal Radiology (https://www.abdominalradiology.org/page/neuroendocrined fp). Dr. Dheeraj R Gopireddy is the Director of Education for the case of the month.

The SAR neuroendocrine DFP members have contributed to the field of academic radiology, and many have published several papers on neuroendocrine tumors in the last year. Drs. Saleh and Morani successfully led the first DFP members' collaborative publication on 'New Frontiers in
Imaging including Radiomics update for Pancreatic Neuroendocrine Neoplasms" in the Abdominal Radiology journal [1]. DFP members also have submitted several abstracts for the upcoming RSNA and workshop proposals for the upcoming annual meeting of SAR. The group is also drafting questionnaires for surveys of various academic institutions to understand and establish the best practices and fill the knowledge gaps in the imaging and reporting of neuroendocrine tumors. Dr. Malak Itani and Dr. Amir Iravani are the Directors for the Imaging Protocol and Reporting Template Management of the DFP. The panel has also started writing its first white paper on pancreatic neuroendocrine tumors under the lead of Dr. Samuel Galgano. Dr. Kedar Sharbidre is leading another DFP collaborative paper on NENs of the GU system.

\section{Look ahead}

Despite the tremendous difficulties of COVID-19 pandemic, our DFP members are enthusiastic, energetic, and active in virtual meetings and various taskforces and are contributing to education and research in the field. The year ahead promises to be equally active and productive. Panel members are looking forward to the success of the white paper on PNENs by the DFP. The DFP is also looking forward to presentations on NENs at RSNA 2020 and SAR 2021. DFP members are also collaborating on educational review articles and original scientific studies. The panel is currently developing a survey for various institutions to gather information on imaging and reporting of PNENs. Dr. Malak Itani is leading the DFP efforts on the questionnaire with potential-related articles in near future. This survey will be distributed to DFP institutions and then to all SAR members following the SAR board approval. The data gathered will be helpful in guiding future best practices in the imaging and reporting of patients with PNENs.

\section{Reference}

1. Saleh, M., Bhosale, P.R., Yano, M. et al. New frontiers in imaging including radiomics updates for pancreatic neuroendocrine neoplasms. Abdom Radiol (2020). https://doi.org/10.1007/s0026 1-020-02833-8

Publisher's note Springer Nature remains neutral with regard to jurisdictional claims in published maps and institutional affiliations. 